\title{
Regional differences in COVID-19 attack and case fatality rates in the first quarter of 2020: a comparative study
}

\author{
Most. Zannatul Ferdous ${ }^{1 *}$, Lakshmi Rani Kundu ${ }^{1}$, Marjia Sultana ${ }^{2}$, Sheikh Jafia Jafrin ${ }^{3}$ \\ ${ }^{1}$ Department of Public Health and Informatics, Jahangirnagar University, Savar, Dhaka-1342, Bangladesh; \\ ${ }^{2}$ Department of Computer Science and Engineering, Begum Rokeya University, Rangpur, Bangladesh; \\ ${ }^{3}$ Department of Geological Sciences, Jahangirnagar University, Savar, Dhaka-1342, Bangladesh
}

\begin{abstract}
Background and Objective: The COVID-19 (Coronavirus disease 2019) outbreak has become a public health threat all over the world. From December 31, 2019 to March 19, 2020, 146 countries were affected. Evidence on the management approaches of current COVID-19 pandemic is still limited though the numbers of affected countries are increasing as the days go by. This study was aimed at determining the attack rate (AR) and case fatality rate (CFR) of Covid-19 in six different regions around the world in the first quarter of 2020. An attempt was also made to provide an overview of the ongoing situation of COVID-19.
\end{abstract}

Methods: The design of the study was mixed approach where a retrospective analysis of surveillance data of six different regions around the world were collected from COVID-19 dashboard of World Health organization, between 31 December 2019 to 19 March 2020 (Time: 2:00 pm. BST [CET: $9 \mathrm{am}$ ]). Besides, other different validated sources (example: Worldometer, Center for Disease Control and Prevention) were used to assess the ongoing situation regarding COVID-19. A statistical software SPSS version 26 was used to analyze the data.

Results: There were a total of 207,860 confirmed cases and 8779 deaths across six different regions around the world from 31 December 2019 to 19 March 2020, with the highest AR of 9.92/100,000 population in Europe region, followed by Asia $(2.7 / 100,000)$, Australia $(1.75 / 100,000)$, North America $(1.42 / 100,000)$, South America $(0.23 / 100,000)$ and Africa $(0.06 / 100,000)$ regions. Study results revealed statistically significant association between attack rates and the six regions of the world $(p=0.002)$, meaning that $A R$ varied in the regions around the world. The CFR was high in Europe region (4.81\%), followed by Asia (4.06\%), Africa (2.72\%), South America (1.41\%), Australia (1.12\%), and North America $(0.69 \%)$ regions. Data reviewed from different countries revealed that the highest number of cases was confirmed in the United States, followed by Spain and Italy. The findings revealed that the reported confirmed cases varied widely in different regions of the world.

Conclusion: The severity and variation in -geographical distribution of COVID-19 cases and deaths suggest that urgent response from various government and public health authorities should be taken and research regarding underlying factors determining this severity should be sought for.

IMC J Med Sci 2020; 14(2): 001. EPub date: 17 August 2020

\section{Introduction}

Coronavirus disease 2019 (COVID-19) is an infectious disease caused by severe acute respiratory syndrome
Coronavirus 2 (SARS-CoV-2) [1]. It is a positive-sense single-stranded RNA virus. SARS-CoV-2 is a member of the subgenus Sarbecovirus (beta-CoV lineage B)

*Correspondence: Most. Zannatul Ferdous, Department of Public Health and Informatics, Jahangirnagar University, Savar, Dhaka-1342, Bangladesh.Email: m.zannatul.ferdous@juniv.edu 
[2-4]. The earliest case of COVID-19 infection is thought to have been found on 17 November 2019 in Wuhan, Hubei, China [5]. On 7 January 2020, the COVID-19 was identified as the causative virus by Chinese authorities. Subsequently, the virus spread to all provinces of China and to more than hundreds of other countries in Asia, Europe, North America, South America, Africa, and Oceania [6]. Among the WHO South East Asia region, the number of confirmed cases is showing increasing trend, especially in Bangladesh and in India [7]. In 17 May 2020, the Institute of Epidemiology, Disease Control and Research (IEDCR), reported a total of 22,268 confirmed cases, with 4,373 recoveries and 328 deaths of COVID-19 in Bangladesh, since the first case was reported on the 8th of March 2020 [8]. World health Organization reported that the number of confirmed cases and deaths increased as days go by. The virus causes serious illness mostly among aged people and those with co-morbid conditions [7]. Human-to-human transmission of the virus has been confirmed in all of these regions $[9,10]$. Fever, cough, and shortness of breath are included as common symptoms of this disease [11]. As of March 25, 2020, the overall rate of deaths per number of diagnosed cases was 4.5 percent; ranging from 0.2 percent to 15 percent according to age group or different co-morbid conditions [12]. SARS-CoV-2 was announced as a Public Health Emergency of International Concern by the WHO on 30 January $2020[13,14]$ and on 11 March 2020 the WHO declared it as a pandemic [15]. Literature from previous epidemic studies has revealed that the spreading capacity of COVID-19 virus is much wider than SARS or MERS [16]. The case fatality rates (CFR) for other Corona virus diseases, e.g. SARS- CoV and MERS-CoV were much higher, $10 \%$ and $34 \%$ respectively, whereas the CFR of US seasonal flu was approximately $0.1 \%$, which is much lower than the current CFR for the COVID-19 [17]. Currently, stopping this deadly epidemic of COVID-19 is the highest priority for the global public health community [18].

Till now no vaccine has been developed for COVID19. However, early care and proper treatment in time by the healthcare providers can significantly reduce the morbidity and mortality. So, surveillance of the disease is now the highest priority to detect the regular confirmed cases and deaths. Besides, two epidemiological measurements estimating the CFR and AR for COVID-19 in real time during its epidemic are important. These rates would help to guide the response from various government and public health authorities' worldwide [19]. Thus, this study was undertaken to provide a comparative analysis of the AR and CFR of COVID-19 in six different regions of the world in the first quarter of 2020 with an overview of the ongoing situation of COVID-19 pandemic.

\section{Methods}

Study design, period, and setting: This study was a retrospective analysis of secondary surveillance data spanning from 31 December 2019 to 19 March, 2020. During this period, six regions affected by the outbreak were Asia region (33 countries and 1 territory), African region (33 countries and 2 territories), European region (50 countries and 4 territories), Australia region (2 countries and 2 territories), North American region (12 countries and 1 territory), South American region (16 countries and 10 territories) and 1 International Conveyance (Cruise Ship).

Data source and management: Data of COVID-19, both on confirmed cases and deaths in the above mentioned regions were collected from coronavirus disease situation dashboard/database namely Worldometer, World Health Organization and European Center for Disease Control [20-23]. Data was first imported in MS Excel and then exported in SPSS version 26 for analysis. The processes for selecting the final dataset are shown in Figure-1.

Study population, and definition of key variable: The study population comprised of people identified as COVID-19 cases during the outbreak period. In accordance with the European Center for Disease Control guidelines for preparedness and response to COVID-19 outbreak, a COVID-19 case was defined as a person with laboratory confirmation of virus causing COVID-19 infection, irrespective of clinical signs and symptoms [22]. 


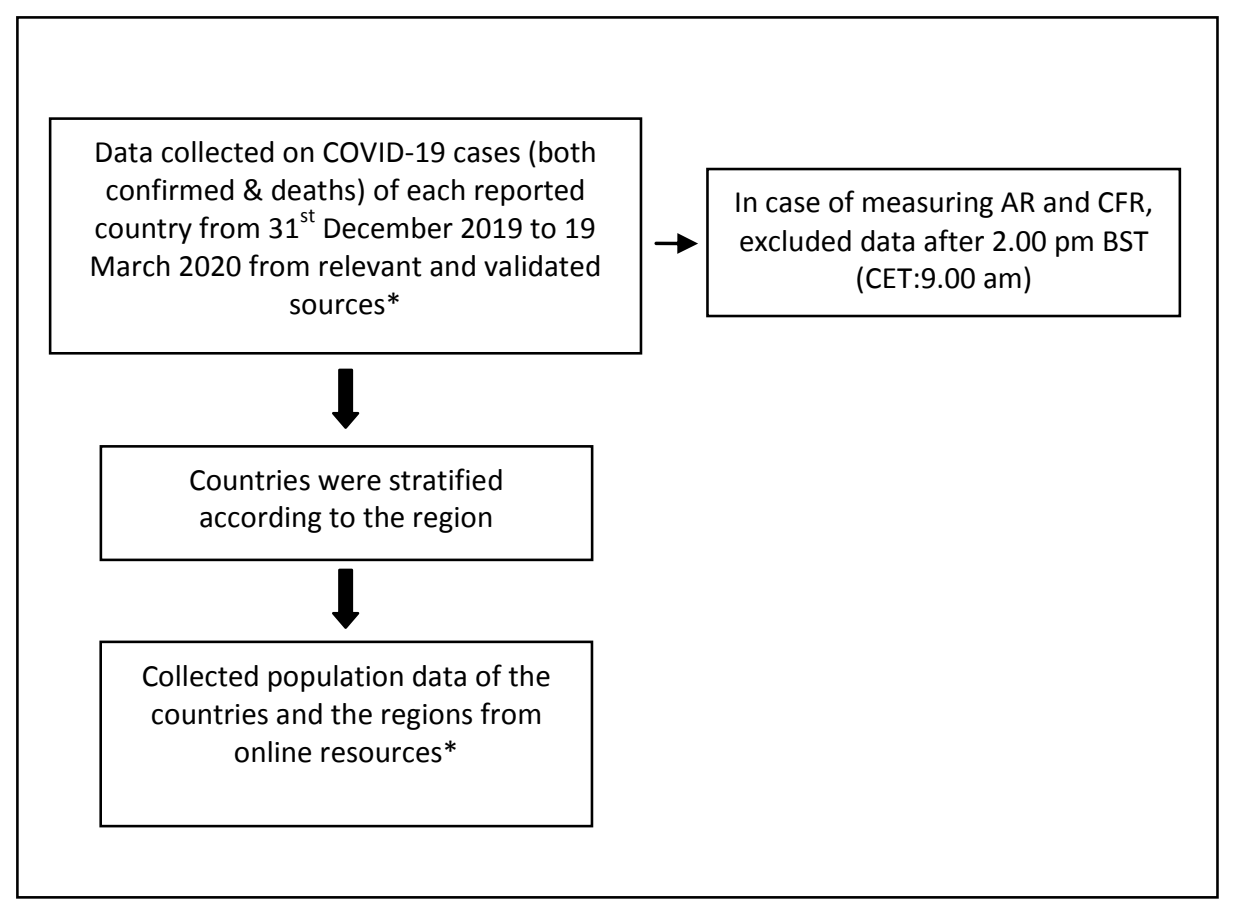

Fig-1: The selection process of data, 31 December 2019 - 19 March 2020; *[20-23].

Statistical analyses: All statistical analysis was performed in SPSS version 26. Case fatality rate was expressed as percentage. Fisher-exact test was used to show the differences of attack rates in the selected regions around the world. A p-value of less than 0.05 was considered statistically significant. As the data includes only the printed and published information, no formal ethical clearance was needed.

\section{Results}

Thirty four countries and 1 territory in Asia region, 33 countries and 2 territories in African region, 50 countries and 4 territories in European region, 2 countries and 2 territories in Australia region, 16 countries and 10 territories in North America, 12 countries and 1 territory in South American region and 1 International Conveyance (Diamond Princess Cruise Ship) have been affected by the COVID-19 outbreak, resulting in a total of 207,860 cases and 8779 deaths till 19 March 2020. Table 1a highlights the reported coronavirus cases and deaths by region till 19 March 2020. The outbreak was divided by six regions and a Cruise ship called the Diamond Princess. Notably, the majority of coronavirus cases occurred in Asia region with a peak at 112,021 cases and 4,546 deaths with an AR of 2.57/100,000 population and a CFR of $4.06 \%$. Though the number of cases were more in Asia both AR and CFR were highest in Europe among the six regions. The second highest numbers were reported in Europe with 84,968 cases and 4,084 deaths. The lowest numbers were reported in Australia with 538 cases and 6 deaths. The second lowest numbers were found in Africa with an AR of $0.06 / 100000$ population but showed an alarming CFR of $2.72 \%$ (Table-1a).

The highest number of deaths $(3,242)$ was recorded in China with an attack rate of $5.64 / 100,000$ population and a case fatality rate of $3.99 \%$ in Asia region during the study period. In Europe, the most affected country was Italy with 35,713 cases and 2,978 deaths (Table-1b). The Diamond Princess Cruise ship was affected immensely; there were 712 cases and 7 deaths out of 3,711 passengers and crew members. 
Table-1a: Distribution of COVID-19 cases showing AR and CFR by regions from 31 December 2019 to 19 March 2020

\begin{tabular}{lcccccc}
\hline Region & $\begin{array}{c}\text { Number of } \\
\text { reporting } \\
\text { Countries/ } \\
\text { Territories }\end{array}$ & Population* & $\begin{array}{c}\text { Cases } \\
\text { (confirmed) }\end{array}$ & Deaths & $\begin{array}{c}\text { AR/100,000 } \\
\text { population }\end{array}$ & CFR \% \\
\hline Asia & 34 & 4359602980 & 112021 & 4546 & 2.57 & 4.06 \\
Africa & 35 & 1019159326 & 588 & 16 & 0.06 & 2.72 \\
Europe & 54 & 856871939 & 84968 & 4084 & 9.92 & 4.81 \\
Australia & 4 & 30771800 & 538 & 6 & 1.75 & 1.12 \\
North America & 26 & 566645697 & 8021 & 113 & 1.42 & 1.41 \\
South America & 13 & 430756286 & 1012 & 7 & 0.23 & 0.69 \\
Total & 1 & 3711 & $\mathbf{2 0 7 , 8 6 0}$ & $\mathbf{8 7 7 9}$ & & \\
Diamond Princess** & 13 & 712 & 7 & $19 \%$ & 0.98 \\
\hline ** Cruise ship; AR= Attack rate, CFR= Case fatality rate; *Population source: (Worldometer, 2020)
\end{tabular}

Table-1b: Distribution of COVID-19cases in countries having cases more than 1000 from 31 December 2019 to 19 March 2020

\begin{tabular}{lcccc}
\hline Country & Confirmed Cases & Deaths & AR/100000 population & CFR \% \\
\hline China & 81174 & 3242 & 5.64 & 3.99 \\
Italy & 35713 & 2978 & 59.07 & 8.34 \\
Iran & 17361 & 1135 & 20.67 & 6.54 \\
Spain & 13716 & 598 & 29.34 & 4.36 \\
Republic of Korea & 8413 & 84 & 16.41 & 1.00 \\
Germany & 8198 & 13 & 9.78 & 0.16 \\
France & 7652 & 244 & 11.72 & 3.19 \\
United States of America & 7087 & 100 & 2.14 & 1.41 \\
Switzerland & 3003 & 21 & 34.7 & 0.70 \\
The United Kingdom & 2626 & 103 & 3.87 & 3.92 \\
Netherlands & 2051 & 58 & 11.97 & 2.83 \\
Austria & 1646 & 4 & 18.28 & 0.24 \\
Belgium & 1486 & 14 & 12.82 & 0.94 \\
Norway & 1423 & 3 & 26.25 & 0.21 \\
Sweden & 1279 & 3 & 12.66 & 0.23 \\
Denmark & 1044 & 4 & 18.02 & 0.38 \\
\hline
\end{tabular}

Note: AR: Attack rate; CFR: Case fatality rate

Figure-2, presents the cumulative cases of novel coronavirus diseases by date. The graph shows an increasing trend; on $25^{\text {th }}$ January there were 1.3 thousand cases, which enhanced to 7.8 thousand cases by $30^{\text {th }}$ January. In February, total case number became 85.6 thousand. In middle of March it increased sharply to 153.6 thousand cases.
Primary outcomes included AR and CFR and were presented in accordance to regions in Table 2 . Coronavirus AR (per 100,000) was less than 1 person among $55.9 \%$ countries in the Asia region. It lies between 1 to 4.99 persons among $20.6 \%$ countries in that region. Attack rate of more than 20 people were reported in $2.9 \%$ countries in this 


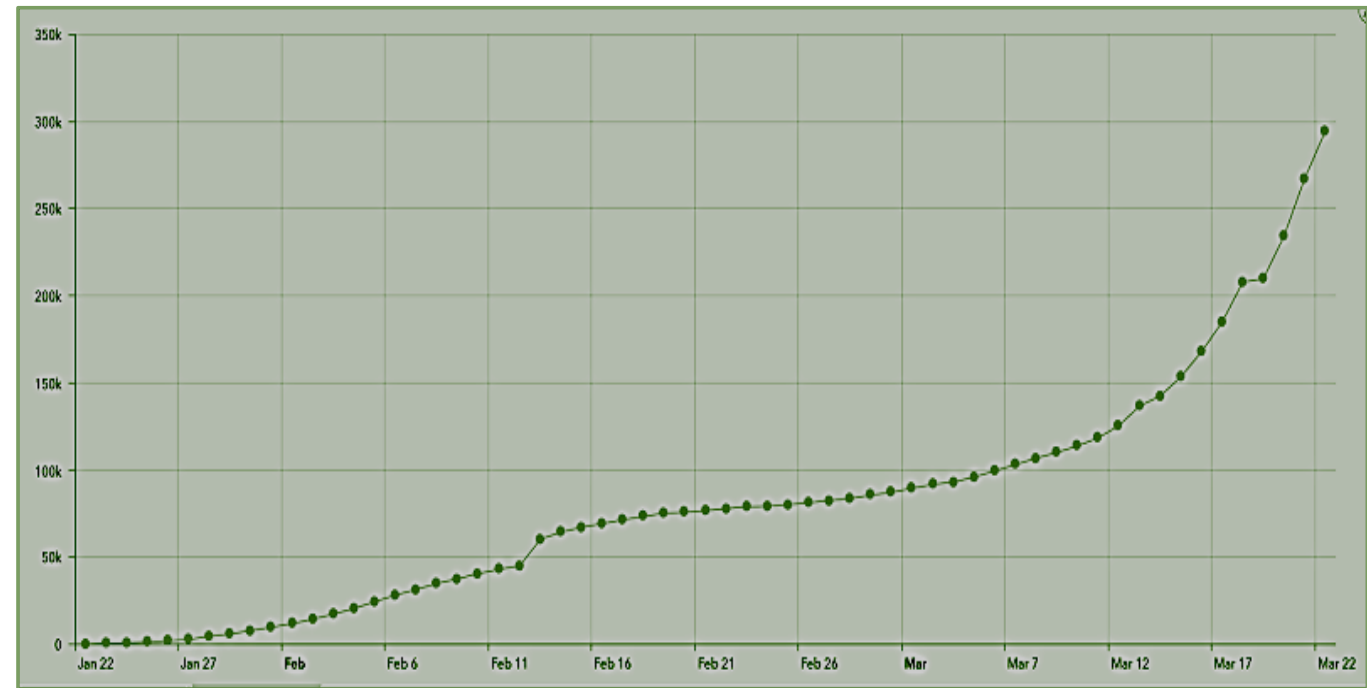

Fig-2: Time series of novel coronavirus (COVID-19) situation

Table-2: Association between Regions and Attack rate

\begin{tabular}{|c|c|c|c|c|c|c|c|}
\hline \multicolumn{6}{|c|}{ Attack Rate (\%) } & \multirow[b]{2}{*}{ Total } & \multirow{2}{*}{$\begin{array}{c}p- \\
\text { value }\end{array}$} \\
\hline Regions & $<1$ & $\begin{array}{c}1.0 \text { to } \\
4.99\end{array}$ & $\begin{array}{c}5.00 \text { to } \\
9.99\end{array}$ & $\begin{array}{c}10.0 \text { to } \\
19.99\end{array}$ & $20+$ & & \\
\hline Asia & 19(55.9) & $7(20.6)$ & $3(8.8)$ & $4(11.8)$ & $1(2.9)$ & 34 & \\
\hline Africa & $28(80.0)$ & $4(11.4)$ & $1(2.9)$ & $0(0.0)$ & $2(5.7)$ & 35 & \\
\hline Europe & 17 (31.5) & $13(24.1)$ & $4(7.4)$ & 9 (16.7) & $11(20.4)$ & 54 & רחת ח \\
\hline Australia & $2(50.0)$ & $2(50.0)$ & $0(0.0)$ & $0(0)$ & $0(0)$ & 4 & 0.002 \\
\hline North America & $13(50.0)$ & $9(34.6)$ & $2(7.7)$ & $0(0.0)$ & $2(7.7)$ & 26 & \\
\hline South America & 10(76.9) & $3(23.1)$ & $0(0.0)$ & $0(0.0)$ & $0(0.0)$ & 13 & \\
\hline
\end{tabular}

Using Fisher exact test, $p<0.05$ was considered statistically significant.

region. In African region, less than 1 person was affected with COVID-19 among $80 \%$ of the countries. In South America, $76.9 \%$ countries attack rate was less than 1 , no countries reported attack rate of $\geq 5.00$ people per 100,000 . Data in Table- 2 revealed that the attack rates differed significantly in different regions of the world $(p<0.005)$.

This section provides an overview of the ongoing pandemic of COVID-19 in selected American, European and South East Asian countries. Data and literature review suggested that the number of confirmed cases and deaths were increasing in countries of different regions all over the world (Figure-3a and $3 \mathrm{~b}$ ). The highest numbers of confirmed cases were found in the United States, followed by Spain, and Italy (Figure-3a). Figure-3b revealed that during the study period the highest and lowest numbers of deaths were in the United States $(91,593)$ and in China (4634) respectively among the affected countries. 


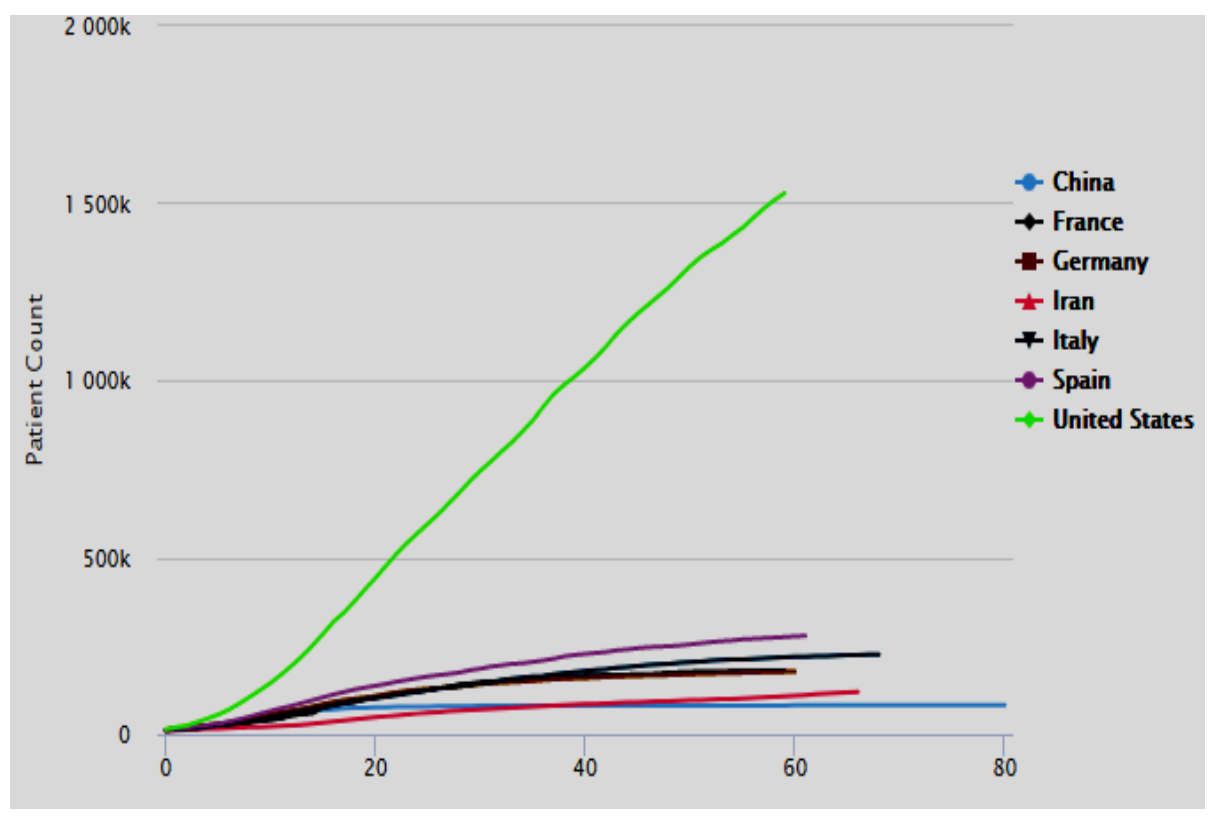

Fig-3a: Cumulative number of cases by number of days [20]

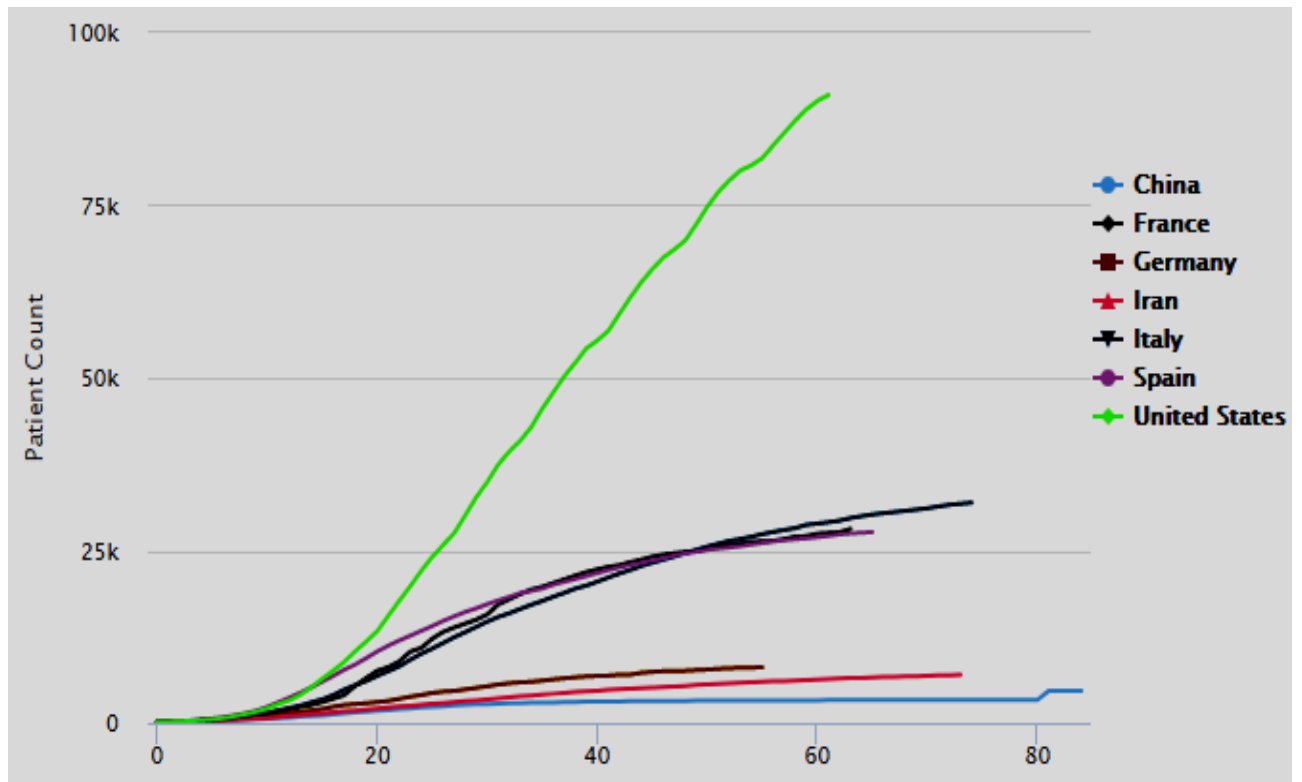

Fig-3b: Cumulative number of deaths [20]

Figure-4a shows the growth of COVID-19 confirmed cases in the selected South East Asian countries starting from the day they reported 100 confirmed cases. In Figure- $4 b$, the distribution of the number of confirmed cases and deaths of COVID-19 in Bangladesh were presented, it was observed that by the end of first week of May, 2020 the total active cases, deaths and recoveries were 12,550, 


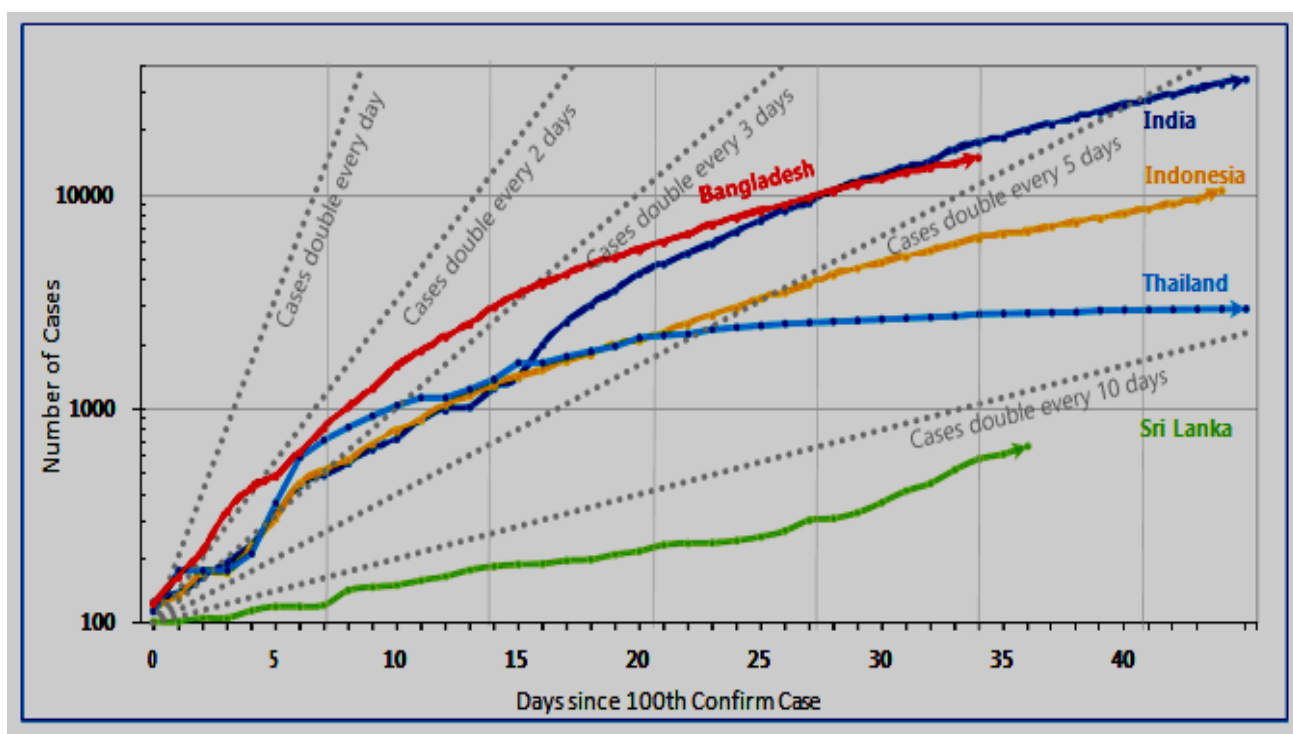

Fig-4a: The growth of COVID-19 confirmed cases in selected South East Asian countries [23]

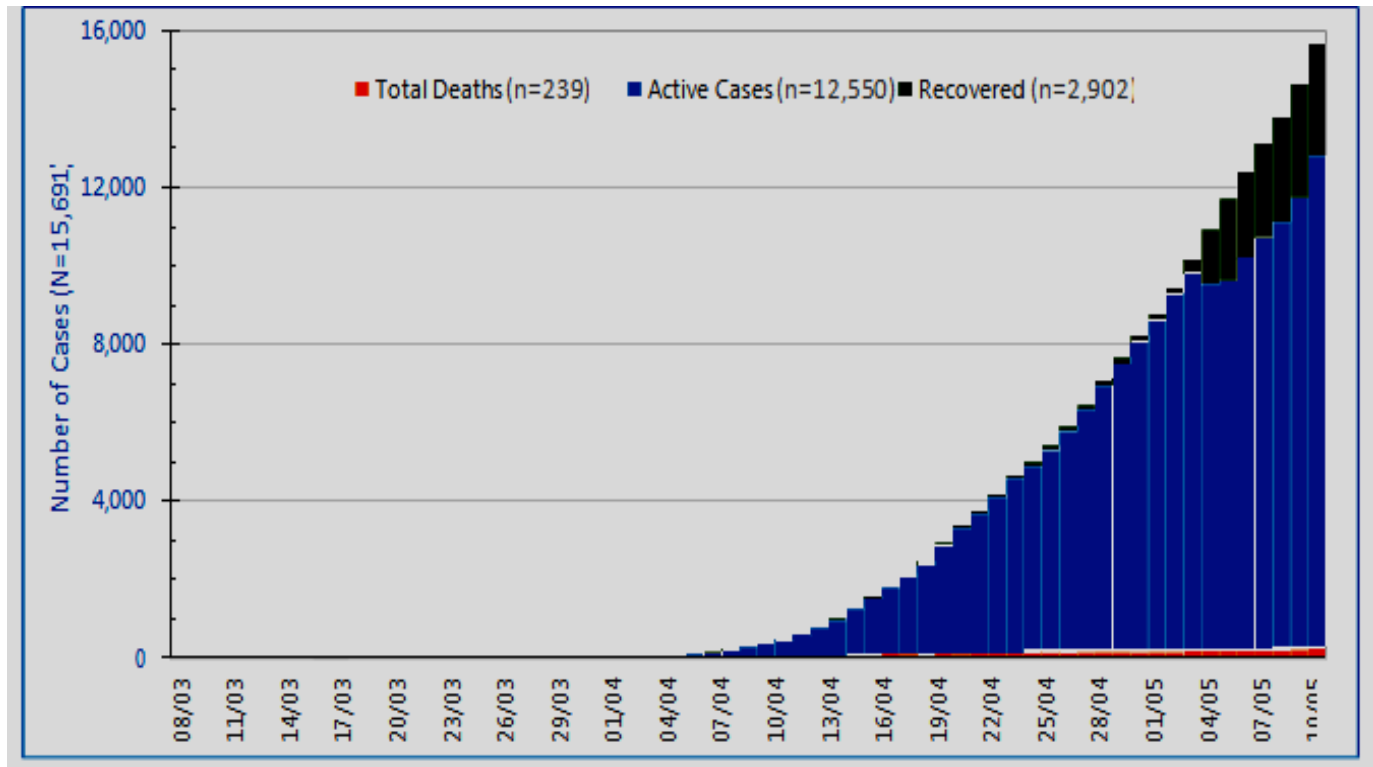

Fig-4b: The figures showing the daily distribution of reported confirmed COVID-19 cases, total deaths and recoveries, Bangladesh [23]

239, and 2902 were respectively. Surprisingly, among the countries in South East Asian region, infection rate in Bangladesh stayed low until the end of March (first case identified 8 March, 2020) but a steep rise was seen afterwards. By April 9, the case number reached to 100 and within next two days the number had doubled (case doubling time).

\section{Discussion}

COVID-19 was first reported in December, 2019, in Wuhan, in the Hubei province of China, and spread very rapidly to all other places in Hubei, as well as all other provinces, autonomous regions, municipalities, and special administrative regions of China. Then it 
spread not only within China but also broke out all over the world. During any epidemic, it is very difficult to estimate CFR. However, this measurement is helpful for guiding responsible authorities to take necessary preventive measures. Besides estimating CFR, attack rate and secondary attack rate (SAR) are also important pieces of data that help to guide in getting the necessary response from various government and public health authorities worldwide. This study was carried out to provide a comparative description of COVID-19 AR and CFR among six WHO regions. The reported confirmed cases are increasing day by day all over the world. On 25th January there were 1.3 thousand cases but after 3 weeks (on February 15) it increased to 67.2 thousand cases. On March 15, it became 153.6 thousand cases. As of 19 March 2020, there were 207.8 thousand confirmed cases in six regions [21].

The report showed that $66 \%$ countries in Asia region, $61 \%$ countries in Africa region, 98\% countries in Europe region, $14.29 \%$ in Australia region, $69.57 \%$ in North America region and $100 \%$ countries in South America region have been affected by this pandemic. As of March 19, 2020, there have been 207,860 confirmed cases and 8779 deaths in those regions. A total of 146 countries and 20 territories in six regions and 1 International Conveyance (Diamond Princess Cruise Ship) have been affected by the COVID-19.

Thus worldwide, this new disease has brought tremendous pressure and terrible consequences on the public health and medical systems of the affected countries. Current estimates of CFR for COVID-19 vary depending on the datasets and time periods examined. A previous study on nearly 1100 patients from China suggested a CFR of 1-4\% [24]. The present study during the study period (31 December 2019 to19 March 2020) observed the CFR and AR in China as 3.99\% and 5.64\% respectively. The highest CFR was in Italy (8.34\%), followed by Spain (6.54\%) and Iran (4.36\%). Among the six WHO regions highest CFR was found in Europe region $(4.81 \%)$, followed by Asia (4.06\%) and Africa region (2.72\%) during that time period. From a previous dataset of 44,672 confirmed cases in China, a report from the Chinese Center for Disease Control and Prevention (CDC) estimated an overall CFR of 2-3\%. Nevertheless, the study pointed out that the rate varied by location and intensity of transmission (for example, 2-9\% in Hubei vs. $0-4 \%$ in other areas of China), in different phases of the outbreak (for example,4-14.0\% before Dec 31, 6-15.0\% for Jan 1-10, 5-7\% for Jan 11-20, 1-9.0\% Jan for 21-31, and 0-8\% after Feb 1), as well as by sex $(2-8 \%$ for males vs.1-7\% for females) $[19,25]$.

Estimates of CFR differ from one country to another because of differences in implementation of preventive, control, and mitigation measures. Also, the preparedness and availability of health care facilities substantially affects the CFR. Besides, previously published studies identified delay in detection of infected cases as one of the key factors of spreading the virus and worse outcome of the disease [26].

Considering another objective of the study, we searched for data of ongoing situation of COVID-19. The data reviewed suggests that the number of confirmed cases and deaths had increased in America and Europe. However, the AR and CFR were less in some regions during the period of the study as the number of affected countries and confirmed cases was low. During the selected period of the study, a slow increasing rate of the confirmed cases and deaths in Asia region especially in Bangladesh was observed. However, from the time between preparation of the paper and submission, the number of confirmed cases and death were found to have been increased in different regions mainly in India and Bangladesh [20].

Our study has limitations. First, this study used secondary data sets which varied with time. Second, we did not report the CFR according to different age groups. Third, CFR differs with delay in detection of case, transmission rate of infection, prevention and mitigation strategies of a country, all of which were not adjusted in this study. Fourth, only two indicators were analyzed. Thus, interpretation of the findings is limited. Fifth, the death from COVID-19 with comorbid conditions were not excluded, influencing the CFR. Sixth, the reasons in the differences in the number of confirmed cases and deaths in six regions were not explored. Finally, the reviewed data did not provide a representative picture of the country-wise 
differences of the number of cases and deaths and the management options taken by the respective country. So, further situation analysis is needed to understand the overall dynamics of the COVID-19 pandemic.

In summary, this study found that the case fatality rate and attack rate varied across different regions of the world. As there is no specific treatment against COVID-19 yet, the only solution is to keep the infected cases as low as possible. However, cases are still increasing all over the world. So, all the concerned authorities and public should come forward and work united to get rid of this COVID-19 and to ensure a pandemic free world.

\section{Conflict of interest}

The authors declare that they have no potential conflict of interest for the publication of this article.

\section{Author contributions}

MZF and LRK: Conceptualization, methods, data searching, writing-original draft, editing, and validation. MS: Editing. SJJ: Writing-original draft.

\section{References}

1. World Health Organization. Naming the coronavirus disease (COVID-19) and the virus that causes it. Geneva: World Health Organization; 2020.

2. Hui DS, Azhar El, Madani TA, Ntoumi F, Kock R, Dar O, et al. The continuing 2019-nCoV epidemic threat of novel coronaviruses to global health - The latest 2019 novel coronavirus outbreak in Wuhan, China. Int J Infect Dis. 2020; 91: 264-266. [Editorial].

3. Gorbalenya AE, Baker SC, Baric RS, de Groot RJ, Drosten $C$, Gulyaeva $A A$, et al. The species of severe acute respiratory syndrome-related Coronavirus: classifying 2019-nCoV and naming it SARS-CoV-2. Nature Microbiology. 2020; 5(4): 536-544.

4. Wong ACP, Li X, Lau SKP, Woo PCY. Global epidemiology of bat coronaviruses. Viruses. 2019; 11(2): 174.
5. Josephine M. Coronavirus: China's first confirmed Covid-19 case traced back to November 17. South China Morning Post. 2020.

6. Johns Hopkins CSSE. Coronavirus COVID-19 Global Cases by Johns Hopkins CSSE 1. Johns Hopkins University. 2020.

7. World Health Organization. COVID-19 situation. Bangladesh: World Health Organization; 2020. Report No.: 9.

8. Institute of Epidemiology, Disease Control and Research (IEDCR), Dhaka, Bangladesh. Corona Info. corona.gov.bd (in Bengali). Retrieved 3 May2020.

9. Chan JFW, Yuan S, Kok KH, To KKW, Chu H, Yang J, et al. A familial cluster of pneumonia associated with the 2019 novel coronavirus indicating person-to-person transmission: a study of a family cluster. Lancet. 2020; 395: 514-523.

10. Rothe C, Schunk M, Sothmann P, Bretzel G, Froeschl G, Wallrauch $C$, et al. Transmission of 2019-NCOV infection from an asymptomatic contact in Germany. N Engl J Med. 2020; 382(10): 970-971.

11. Centers for Disease Control and Prevention. Coronavirus disease 2019 (COVID-19). CDC Online Newsroom. CDC; 2020.

12. Wikipedia. 2019-20 coronavirus pandemic in mainland China. Wikipedia; 2020.

13. World Health Organization. Statement on the second meeting of the International Health Regulations (2005) Emergency Committee regarding the outbreak of novel coronavirus (2019-nCoV). Geneva: World Health Organization; 2005.

14. Mahtani S, Berger M, O'Grady S, lati $M$. Hundreds of evacuees to be held on bases in California; Hong Kong and Taiwan restrict travel from mainland China - The Washington Post. The Washington Post; 2020.

15. World Health Organization. WHO DirectorGeneral's opening remarks at the media briefing on COVID-19 - 15 April 2020. 2020. 
16. Petrosillo N, Viceconte G, Ergonul O, Ippolito G, Petersen E. COVID-19, SARS and MERS: are they closely related? Eur J Clin Microbiol Infect Dis. 2020; 26(6): 729-734.

17. Lei S, Jiang F, Su W, Chen C, Chen J, Mei W, et al. Clinical characteristics and outcomes of patients undergoing surgeries during the incubation period of COVID-19 infection. $E$ Clinical Medicine. 2020; 21:100331

18. Sohrabi C, Alsafi Z, O'Neill N, Khan M, Kerwan A, Al-Jabir A, et al. World Health Organization declares global emergency: A review of the 2019 novel coronavirus (COVID-19). Int J Surg. 2020; 76: 71-76.

19. Ruan S. Likelihood of survival of coronavirus disease 2019. Lancet Infect Dis. 2020; 20(6): 630-631.

20. Worldometer. Population by country (2020) Worldometer. 2020.

21. World Health Organization. WHO COVID-19 Dashboard. 2020; 1-1.
22. European Center for Disease Control. Case definition and European surveillance for COVID-19, as of 2 March 2020. 2020.

23. World Health Organization. COVID-19 situation. Bangladesh: World Health Organization; 2020. Report No.: 11

24. Liu Y, Eggo RM, Kucharskia AJ. Secondary attack rate and superspreading events for SARS-CoV-2. Lancet. 2020; 395(10227): e47.

25. Guan W, Ni Z, Hu Y, Liang W, Ou C, He J, et al. Clinical characteristics of coronavirus disease 2019 in China. N Engl J Med. 2020; 382: 17081720.

26. Verity $R$, Okell LC, Dorigatti I, Winskill $P$, Whittaker C, Imai N, et al. Estimates of the severity of coronavirus disease 2019: a modelbased analysis. Lancet Infect Dis. 2020; 20(6): 669-677. 